\title{
Thoughts of Lin Yutang contribute on Translation
}

\author{
Huarong ZHANG \\ Foreign Language Department \\ The Engineerig \& Technical College of Chengdu University of Technology \\ Leshan,Sichuan,614000 China
}

\begin{abstract}
Looking at today's translation industry, recognition of the value of his translation theory lack sufficient depth and intensity, and it has always been to the edge of alienation from the mainstream attitude. Lin Yutang's translation of the article attempts to make a new value concept and we find that Chinese and Western science in the history of China's Lin Yutang is clear that the translation of the first modern linguistics and psychology as a theoretical analysis is based on the theory of translation scholar, he undoubtedly provides a new perspective and modern theoretical basis points to China translation theory, so as to enhance the theoretical character of the theory itself.
\end{abstract}

Keywords- Lin Yutang; Translation Studies; sentence translation; the word of God

\section{INTRODUCTION}

Lin Yutang is known as the Great Master, and his writings and translation is quite good. He is bilingual authoring writers in the history of Chinese literature rare. He left to posterity valuable literary fortune that is his profound Chinese culture to the soil, to create a large number of English literatures, and erect a bridge between Western cultural exchanges. At the same time, relying on a wealth of translation theory and practice, Lin Yutang Chinese translation of research in the field has made outstanding contributions. However, due to the limitations of the historical and social reasons, the academic study of Lin Yutang Chinese translation of translation theory and practice has not reached everyone in comparison with other translations depth and size, which is an important position and Lin Yutang outstanding contribution in the field of translation and it is not in anastomosis. So we should think of ways of expanding and deepening understanding of Lin Yutang's translation studies, he inherits and carries forward our traditional translation methods above, so that there are translation of macro and micro studies and the combination of static and dynamic research. Lin Yutang understanding of Western culture and their mastery of both English languages for his consummate skills in translation has laid an important foundation; he first proposed the "beauty" of the standard in the translation industry, enriched the translation aesthetics, and promoted Aesthetics in Translation field. He was an arts advocate translation of Chinese scholars who translated a major impact. This paper combines traditional Chinese view of translation studies and translation in Chinese history scholars on the basis of the translation of aesthetics, from the aesthetic subject, aesthetic object perspective, which examines the body of Lin himself as an aesthetic and translation theory and as an aesthetic, Lin Yutang's works object "Moment in Peking" showed Lin Yutang translation theory and practiced "beauty" expression. In the aesthetic subject, the paper of "beauty" is as the starting point, combining traditional Chinese view of translation studies, focusing on aesthetics and Lin Yutang's translation theory, retroactive translation Chinese traditional culture aesthetics, exploring Lin Yutang absorption of traditional translation culture.

\section{TRANSLATION OF LIN PROPOSED THREE CRITERIA}

Three standard translation by Lin's "faithful", "smooth" and "beauty", focusd on its "beauty" standards, and ultimately come to the aesthetic characteristics of Lin translation theory. Lin Yutang is renowned write, translator and linguist in the world, but for political reasons, he was once the name of the Chinese literary taboo. With the rise of reform and opening up, forestry gradually revived in the mainland, many scholars began to look at an objective point of view and by Lin. However, with respect to the identity of the translator Lin Yutang, these scholars have focused on his literary or cultural outlook. Even the translation of the article by Lin who also either be a part of his research (articles) translated works, such as the Qing Shen Fu "Fu", or study his translation theory, little systematic study of his identity translator academic articles. In view of this, this paper attempts to conduct identity translator Lin Yutang's exhaustive research, from both macro and micro analysis of the characteristics of its English translation practice and objective evaluation of their practice of translation. After detailed analysis, this paper drawn: First, at the macro level, Lin Yutang's Chinese-English translation practice can be divided into pure translation, adaptation, translation and dictionary translation; at the micro, Lin Yutang's excellent translation skills in the wording is stylistic and cultural reproduction of the original term load; Second, Lin in the "import" of advanced Western ideas and technology background insisted English translation, and in the process of translation he bold used "alienation" strategy, which proved that Lin Yutang is never limited to simple translator identity, but consciously let it translate to achieve its cultural 
objectives, namely the spread of bright Chinese culture to the West as much as possible. To Lin Yutang's firm cultural ambassador identity, we should give some recognition.

Lin Yutang is famous modern scholar, writer and translator. He proposed translation is an art, as a faithful translation of the standard, smooth and beauty, and on this basis, the translator made three demands and responsibilities, he opened up a study from a psychological point of view the translation of a new perspective. Lin Yutang has Chinese and Western heritage, and he is familiar with Chinese and Western cultures skills, and engaged in a lot of translation, for communication and the exchange of Chinese and Western cultures he has made tremendous contributions. Lin Yutang's translation thoughts have important historical role in the Chinese translation history, and positive guidance and reference in translation practice.

\section{LIN YUTANG'S TRANSLATION THOUGHTS}

Translation is an art. Lin Yutang is a prolific translator, translation theory, successes; life has published many articles on translation theory. Lin Yutang insisted that the creation of translation is an art perspective, making Chinese translation in the history of use aesthetics to translation theory and practice of representatives. He clearly stated at the beginning, "On Translation", "Translation of events were the first to be conscious that the translation is an art. The art of success will depend on individual skill for the art training. There is also no shortcut to success at all. "It seems according to Lin Yutang, "that is, it should be based on the original style of both its content," especially "not only have to pay attention to what they said and how should note saying," and "a writer, a writer of stylistic grace, this grace is stylistic text the reason for your "so," In the translation of Arts and Letters of people, we must first put their gracious style of pre-translated author identified, try to imitate the complex at the time of translation, and it is the obligation to do the translation of Arts and Letters. "As Lin Yutang "Chinese people", a book said: "Peace and harmony are the characteristics of Chinese art, which originated from Chinese artist's mind," compared with Western art, "the spirit of Chinese art is more elegant, more subtle, more harmony in nature."

China after the May Fourth literary abandon the shackles of traditional culture constructs a new value system, and it already became the consensus of progressive intellectuals, and advanced Western cultures shine, so that traditional Chinese culture is more conservative side abruptly presented come out. Therefore, in order to find a way out of China, the old culture of innovation, and the May Fourth Movement of the Illuminati consciously assume responsibility for introduction of Western culture, translation then becomes a craze on the translation of the altar. Lu Xun, Mao Dun Renew, Lin, who is both a creative force in the literary world, has also become famous translation of the altar, they translate their performance and theoretical explanations for China's translation industry and have made a huge contribution, and thus they promote China Translation Studies development of the theory. In these people, the Lin
Yutang's unique bilingual writing and translation theory presents unique temperament. He learned Chinese and Western heritage, "two Occidental cultures, as one commentary article universe", the Yuanshen China is introduced to the world of popular culture, and also to advance the spread of Western culture to the Chinese public. Chinese and Western cultures have familiar skills, so Lin Yutang's translation theory also has unique color. However, in an overview of today's translation theory, there is recognition of the value of Lin Yutang which lacks sufficient depth and intensity of his translation theory and it has always been to the edge of alienation from the mainstream attitude. Therefore, this article attempts to make Lin Yutang's translation theory find new value, and it is intended to highlight the value of Lin translation theory, rather than introduce its translation theory for the system.

Mr. Lin sought fluent readers who strive to be faithful on the original, and also he stressed that translation should strive for fluent readers responsible for the translation. He sought a thorough understanding of a fresh intelligible English to express the meaning of the original author, but he is not limited to the literal meaning of the original author, but instead he sought to reflect the deep meaning in the translation of the original in order to facilitate the translation on the basis of the original understanding readers. Chinese readers in general is also somewhat difficult to understand, they do not to speak in English to express, but Lin Bahasa Malaysia with its good foundation in a thorough understanding of the premise of the original BARS understand its meaning to the English translation and the translation was very straightforward and in place, the reads mark it very fresh and smooth without chisel. Besides the text name involves a lot of historical figures, Lin did not translate, but the direct use their names so that foreign readers do not understand the history and culture of China and they are confused, and it helps avoid duplication of poor drawbacks, which are reflected in its smooth as thinking readers.

Lin Yutang's translation of Chinese and Western is thought as a unique representative, Mr. Lin Yutang in terms of literary attainments and language training is rare at home and abroad as a Chinese and Western scholars. Such a scholar of translation theory, apparently on the later of translation theory and practice he has an important role in guiding. Lin translation systems insights focused on the publication in 1933 of "linguistic FORUM" in the long essay "On Translation", the Lin Yutang translate is seen as an art, and he paid great attention to the aesthetic characteristics of translation. Artistic success depends largely on the artist's own talent and acquired training about art, the implementation of the translation of this particular art, its success mainly depends on these three points: "The first is the original translator for text and content thorough understanding; the second is the translator of Bahasa Malaysia considerable extent, to include full and smooth up to the Chinese; the third is the training on translation, the translator for translation criteria and surgical problems are legitimate opinions. "In addition to these three outside the points, he believes in the arts we do not need to translate 
much of peremptory norms. Although the translation does not need literally, rigid, in the translation process we must have some standards and methods to define why such a sentence to be translated instead as translation, or how to evaluate the success of a translation.

\section{TRANSLATION FLUENT STANDARDS}

Faithful standard refers to the original translator responsibility, while the translator fluent standard refers readers to their responsibilities. Since the translation of their readership is readers, of course, we consider the target language translation of fluent, if the translators grasp their own language or thorough enough to introduce a mandatory "Europeanization" of the sentence, it will only lead to interrogate translation hard to read, neither fish nor fowl, thus affecting the translation of acceptance and understanding.

Lin Yutang interaction between translation and creation, as translated in terms of the characters and plot of the formation and structure of feminism inspired creation and translation in translation selection criteria and aspects of the translation of the sentence translation. Lin Yutang contribution in terms of cultural exchange is made even more obvious: the history of Chinese literature in modern literature, he promoted the Chinese modern prose style of the formation and development; overseas, his English translation and the creation of Chinese Literature in the United States opened up the theme, it is involved in the construction of American literature. The author hopes that this thesis writing is enabling understanding of Lin Yutang's research community to reach a new height.

\section{CONCLUSIONS}

In the minds of Lin translation, he faithfully demonstrates that translator's subjectivity were reflected in the text selection, translation and translation strategies aim three aspects to highlight this subjectivity and it also contributed to its translation works popular in Europe and America. In today's global cultural blend, review and study the translation of thought, the development of translation services and promoting international cultural exchange is not without benefit. Lin Yutang, the renowned translator and abroad, in a cross-cultural communication has rich, fruitful achievements and rich translation theory for the construction of translation theory, he has an important role in many of the arguments which are still very relevant, as the Chinese translation school development he has made tremendous contributions. In the global context of today's cultural integration, reviewing and researching Lin Yutang's translation thoughts with positive and practical significance for the development of China's translation business promotes international cultural exchange.

\section{References}

[1] Zhou Shibao. Lin Yutang's translation theory [J] Foreign Language Research, 2004,02: 107-110.

[2] Huang Xoapfan. Lin Yutang's translation Talk - Discussion with Associate Prof [J] Sichuan College of Education, 2005,07: 62-65.

[3] Zhang Ying. to the translator's subjectivity of Translation Lin Yutang thought $[\mathrm{J}]$ Hubei University of Economics (Humanities and Social Sciences), 2010,03: 145-146.

[4] Lei Dan, Zhang Qing Lin Yutang's translation of thinking - to "Lin Yutang" as an example [J] literary education (middle), 2014,02: 46.

[5] Zhang Qin. Lin Yutang Ecological Perspective translation under translation studies [D].Central China Normal University, 2014.

[6] Yang Qun. from the translation of Adaptation and Selection see the translator's subjectivity [D].National University of Defense Technology, 2007.

[7] Li Lanjie, Yutang translation and translation studies and interactive creation of [D].Shanghai International Studies University, 2009. 